\title{
Marketing de relacionamento na formação de um diferencial competi- tivo: o caso da cooperativa agrícola mista alfa
}

\author{
Relationship marketing in the formation of a competitive advantage: the case of a \\ joint agricultural cooperative
}

\begin{abstract}
Resumo
Este estudo teve como objetivo verificar a percepção dos clientes sobre os aspectos mais relevantes no seu relacionamento com a Cooperativa Mista Alfa nas questões de fidelização, pós-vendas e a integração destes com a empresa. Para isso, adotou-se uma pesquisa quantitativa e qualitativa, do tipo descritiva, sendo desenvolvida por meio de um estudo de caso em uma amostra por acessibilidade, totalizando 66 clientes da referida cooperativa. Os resultados obtidos apontaram que o marketing de relacionamento é de extrema importância no processo de integração do cliente com a cooperativa, onde a rapidez na solução de problemas foi apontada como um dos fatores mais importantes para um bom relacionamento. Concluiu-se que, entre outros aspectos, os mais valorizados pelos clientes são: o contato pessoal, a visita dos engenheiros agrônomos, o relacionamento entre o agricultor e a cooperativa e, ainda, a confiança nos produtos e serviços oferecidos.
\end{abstract}

Palavras-chave: Marketing; Cliente; Marketing de Relacionamento.

\begin{abstract}
This study aimed to verify the customers' perception of the most important aspects in your relationship with the Cooperative Alfa on issues of loyalty, aftermarket and integrating these with the company. For this, we adopted a quantitative and qualitative research, descriptive, being developed through a case study on a sample of 66 customers totaling accessibility of the cooperative. The results showed that relationship marketing is of utmost importance in the process of integrating the client with the cooperative, where speed in solving problems was appointed as one of the most important factors for a good relationship. It was concluded that among other aspects, the most valued customers are: personal contact, the visit of the agronomists, the relationship between the farmer and the cooperative and also confidence in the products and services offered.
\end{abstract}

Keywords: Marketing; Costumer; Relationship Marketing.

Recebido: 29/08/2014 Aceito: 17/10/2014

\footnotetext{
Vinicius Balconi Scaramussa ${ }^{1}$, Élio Sérgio Denardin², Flaviani Souto Bolzan Medeiros ${ }^{3}$, Patrícia Schrippe ${ }^{4}$ e Andreas Dittmar Weise $^{5}$

${ }^{1}$ Centro Universitário Franciscano, Bacharel em Administração - vinicius.scaramussa@hotmail.com

${ }^{2}$ Centro Universitário Franciscano, Mestre em Filosofia - eliodenardin@hotmail.com

3,4 Universidade Federal de Santa Maria, Mestranda no Programa de Pós-Graduação em Engenharia de Produção - flavianiadm@ gmail.com / pschrippe@gmail.com

${ }^{5}$ Universidade Federal de Santa Maria, Doutor em Engenharia Civil - mail@adweise.de
} 


\section{Introdução}

$\mathrm{U}$ m cenário de constantes transformações no mundo dos negócios vem ocorrendo, estando em curso uma revolução sobre como você, seus colegas e concorrentes veem os clientes e, mais importante ainda, como os clientes estão vendo vocês e a eles mesmos. Até alguns anos atrás, o cliente era aquele indivíduo que comprava bens ou serviços de sua empresa. Parecia algo muito simples, mas a globalização começou a se movimentar rapidamente para todos os lados na década de 1990, com a entrada da internet no mercado principal (GREENBERG, 2001).

Nesse sentido, Kellezi (2014) corrobora que hoje os mercados e as relações comerciais tornaram-se globais. Deste modo, em uma economia globalizada, é importante estar atento às mudanças no cenário econômico, onde a cada dia tem-se o aumento da disputa e concorrência do mercado. Assim sendo, Barrionuevo (2004) comenta que é necessário conhecer a fundo os clientes, o que eles necessitam, em que momento irão precisar, quais são as suas preferências, ou seja, o que realmente é necessário fazer para atender às suas necessidades.

Portanto, pode-se dizer que a empresa que não atentar a estes detalhes está indo rumo ao fracasso, onde até os meios utilizados para a aproximação e manutenção do relacionamento são importantes neste longo processo de satisfação total do cliente. É importante saber como funcionam os mercados empresariais e de que forma operam, como também como se dá o relacionamento entre fornecedores e clientes.

Considerando que esses clientes estão cada vez mais exigentes, é importante que as empresas estejam preparadas para recebê-los, até mesmo para não perderem mercado para a concorrência. Nesse cenário, o marketing de relacionamento tornou-se o ponto de vista dominante no mundo dos negócios, bem como dos estudos de marketing (MÖLLER, 2013). Isso se deve ao fato de que os esforços de marketing de relacionamento geram relações mais fortes entre clientes e vendedores que, por sua vez, melhoram o desempenho incluindo, ainda, o crescimento das vendas, participação de mercado e no lucro (BONNEMAIZON; COVA; LOUYOT, 2007).

Diante do exposto, o presente estudo tem como objetivo verificar a percepção dos clientes sobre os aspectos mais relevantes no seu relacionamento com a Cooperativa Mista Alfa nas questões de fidelização, pós-vendas e a integração destes com a empresa.

A preocupação por parte das empresas em compreender a satisfação dos clientes é cada vez maior. Sendo assim, observa-se uma importante questão a ser verificada, no caso, analisar a influência do bom relacionamento com os clientes para fidelizá-los. Para abordar essa temática é necessário estudar uma série de fatores que podem levar o cliente a ficar satisfeito ou não com o resultado final do serviço, ou até mesmo com a empresa em si

Para tanto, este trabalho está estruturado da seguinte forma: logo após a introdução, encontra-se exposto o referencial teórico, contemplando tópicos referentes ao marketing, clientes, bem como o marketing de relacionamento e a questão da fidelização do cliente. Na sequência, apresenta-se a metodologia utilizada para realização da pesquisa; em seguida, a análise e discussão dos resultados subdivididos em caracterização da cooperativa, perfil dos clientes entrevistados e relacionamento do cliente com a cooperativa. E, por último, as considerações finais obtidas a partir do estudo realizado.

\section{Referencial teórico}

\subsection{Marketing}

Parte-se do entendimento de que, antes de abordar o tema marketing de relacionamento se faz necessária a compreensão do conceito de marketing. Deste modo, segundo Etzel, Walker e Stanton (2001), marketing é o conjunto das atividades de negócios desenvolvidos para planejar, dar preço, promover e distribuir produtos que satisfaçam os desejos do mercado alvo e atingir os objetivos organizacionais.

Quando se fala em marketing se está pensando nas estratégias usadas por uma empresa para a colocação de um determinado produto ou serviço no mercado, com o objetivo de atender e satisfazer às demandas $\mathrm{e}$ necessidades de seu público-alvo, identificado como cliente (YANAZE, 2007).

Sob essa perspectiva, Las Casas (2012) corrobora que um dos principais elementos do marketing é sua orientação para os consumidores. Essa orientação mercadológica é fundamental para o sucesso para qualquer empreendimento. $\mathrm{O}$ autor ainda ressalta a importância do marketing mix ou composto de marketing, representado por produto, preço, praça e promoção. Esses itens são as principais etapas em todos os tipos de comercialização.

Complementarmente, Churchill Junior e Peter (2013) esclarecem que existem dois tipos de clientes que participam das trocas comerciais, a saber: (1) em primeiro lugar há os compradores organizacionais, que compram produtos para o funcionamento de suas próprias empresas (como suprimentos de escritório, máquinas, redes de computador) ou para vender a outras organizações ou consumidores.; (2) em segundo lugar há os consumidores, que compram bens e serviços para seu próprio uso ou para presentear outras pessoas. Os consumidores incluem indivíduos e famílias, que fazem compras para satisfazer suas necessidades e desejos, resolver seus problemas ou melhorar sua vida.

\subsubsection{Clientes}

Para as organizações, os clientes são a razão de existir 
da mesma, por isso, é fundamental que se conheçam suas características. Conhecer o perfil dos clientes é de grande importância para que as empresas consigam satisfazer seus desejos e necessidades, conquistando-os e fazendo com que estes se tornem fiéis.

Entretanto, atender os clientes vem se tornando uma tarefa cada vez mais complexa nos últimos anos, isso porque além do grande discernimento dos consumidores, também são lançados constantemente novos produtos e serviços no mercado (GRIFFIN, 2007).

Portanto, as organizações lutam todos os dias para inovar no sentido de manter seus clientes e ainda atrair novos. Na concepção de Silva et al. (2011), as organizações de sucesso têm os clientes como centro do seu pensamento estratégico. Eles representam a sua razão de ser. Os clientes podem ser pessoas físicas, organizações privadas ou estatais, ou mesmo organizações sem fins lucrativos que estejam dispostas a comprar bens e serviços por um determinado valor.

Devido a todo esse valor atribuído ao cliente, as empresas necessitam mantê-lo, pois sua perda fará muita falta para a empresa. Para Kotler e Armstrong (1999), um cliente perdido representa mais do que a perda da próxima venda; a empresa perde o lucro de todas as compras futuras daquele cliente, para sempre. Portanto, valor do cliente é o valor total presente de todos os clientes da empresa ao longo do tempo. Segundo Hoeffler e Keller (2002 apud Kotler e Keller 2007) existem três elementos condutores do valor do cliente:

A) Dimensão do valor: é a avaliação objetiva feita pelo cliente da utilidade de uma oferta com base em sua percepção de custo- benefício. Os componentes da dimensão do valor são qualidade, preço e conveniência. Cada setor deve definir os fatores específicos subjacentes a cada componente a fim de encontrar programas para melhorar a dimensão do valor. A dimensão do valor proporciona sua maior contribuição ao valor do cliente quando os produtos são diferenciados e quando são mais complexos e precisam ser avaliados. Isso se dá, principalmente, nos mercados empresariais;

B) Brand equity: é a avaliação subjetiva e intangível que o cliente faz da marca, acima e além do valor percebido objetivamente. Os componentes do brand equity são conscientização de marca, postura do cliente com relação à marca e percepção do cliente quanto à ética da marca; e

C) Relationship equity: é a tendência que o cliente tem de prender à marca, acima e além das avaliações objetiva e subjetiva sobre o valor. Os componentes do relationship equity incluem programas de fidelidade, de reconhecimento e tratamento especiais, de construção de comunidades e de conhecimento.

Esse somatório de elementos integram a gestão de valor, a gestão de marca e a gestão de relacionamento dentro de um foco centrado no cliente. As empresas podem decidir quais elementos devem reforçar para obter o melhor resultado.

\subsection{Marketing de relacionamento}

A definição de marketing de relacionamento tem sido dinâmica ao longo dos anos (MUSA; BONIFACE; TANAKINJAL, 2014). Sob esse enfoque, para Las Casas (2013), marketing de relacionamento são todas as atividades de marketing destinadas para manter um cliente em situações de pós-venda. Enquanto que os autores Sheth, Parvatiyar e Sinha (2012), e Agariya e Singh (2011) consideram o marketing de relacionamento um processo contínuo, engajado em atividades e programas para criação de valor visando a retenção de cliente.

Complementarmente, a respeito das estratégias de marketing de relacionamento, estas são normalmente concebidas para coletar informações a fim de ajudar as empresas a identificar e reter os melhores clientes, maximizar o valor do cliente e lucratividade (ASHLEY et al., 2011).

Para Madruga (2010), a empresa que pretende praticar o marketing de relacionamento precisa desenvolver as seguintes funções:

A) Elaboração conjunta de uma nova visão e cultura empresarial voltada para os clientes e parceiros;

B) Construção de objetivos de marketing de relacionamento conectados à visão e sempre de natureza límpida;

C) Estabelecimento das estratégias de marketing de relacionamento voltadas para a criação de valor e em conjunto com os clientes;

D) Implementação de ações táticas com foco no relacionamento colaborativo com clientes;

E) Obtenção de benefícios mútuos, isto é, empresas e clientes tiram proveito da cooperação ocorrida em vários momentos de contato;

F) Direção da ação, capacitação e envolvimento dos colaboradores da empresa para relacionamentos superiores.

Segundo Silva e Zambon (2006), a gestão do relacionamento com o cliente pode ser entendida como o gerenciamento dos meios utilizados para se estabelecer e mensurar os contatos com os clientes, sendo considerado que cada contato pode ter como origem o próprio cliente ou a organização. O relacionamento com o cliente se torna mais notável nas organizações com o desenvolvimento do Customer Relationship Management (CRM), que entende as interações entre demanda e oferta (cliente e organizações) e as ferramentas tecnológicas necessá- 
rias para melhor aproveitá-las. Para o mesmo autor, é importante destacar também que a implementação do CRM pode trazer diversas vantagens de marketing para a organização, tais como:

A) Reduzir custos com propaganda;

B) Diminuir os riscos de comunicação (propaganda);

C) Melhorar a abordagem de clientes específicos por se concentrar em suas necessidades e na capacidade de atendê-las;

D) Aumentar a capacidade de mensurar o resultado de determinada campanha;

E) Dar suporte à organização para competir por clientes com os serviços e diferenciais agregados que fornece, não apenas por preço;

F) Acelerar o processo de desenvolvimento e comercialização de produtos; e

G) Utilizar mais eficientemente o banco de dados de marketing, que armazena, processa e distribui informações relevantes para quaisquer áreas organizacionais solicitantes. resolver problemas.

Para se fazer um bom marketing de relacionamento, no entendimento de Las Casas (2013), é necessário que a empresa mantenha um atualizado banco de dados e tenha muita preocupação com a qualidade, pois somente com produtos ou serviços de qualidade se mantêm clientes.

Se o serviço não tiver qualidade, o cliente ficará insatisfeito e, com isso, poderá comentar com outros futuros clientes, assim, conforme Sheth (2001), se um número suficiente de clientes ficar insatisfeito, não só eles deixarão de comprar da empresa, mas toda a sociedade a condenará e poderá até penalizá-la". Portanto, é de suma importância a transparência nas ofertas e nos serviços prestados a fim de evitar ao máximo o descontentamento dos clientes.

\subsubsection{Fidelização}

Manter a fidelidade dos consumidores é um dos desafios impostos pela concorrência, são inúmeras empresas ofertando produtos similares e atuando sobre um público-alvo em comum, gerando a necessidade de cada organização buscar aperfeiçoamentos constantemente.

De acordo com Las Casas (2013), o conceito de fidelidade significa que os clientes continuam a comprar de uma empresa porque acreditam que ela tenha bons produtos ou serviços. Não a abandonam e, muito pelo contrário, estão geralmente dispostos a cooperar. Para

Quadro 1: Riscos dos programas de fidelização

\begin{tabular}{|l|l|}
\hline a) & Falta de experiência por parte dos responsáveis; \\
\hline b) & Tecnologia inadequada para gestão do programa; \\
\hline c) & Visão de lucros em curto prazo; \\
\hline d) & Canais de contato mal dimensionados; \\
\hline e) & Falta de informação do programa para as áreas operacionais; e \\
\hline f) & Regras confusas ou pouco claras para os consumidores. \\
\hline
\end{tabular}

Fonte: Adaptado Las Casas (2013).

Da amizade e confiança estabelecidas são gerados os negócios entre si, criando também, lealdade à marca ou produtos da empresa, maximizados ao longo do tempo. Deste modo, segundo Da Silva e Zambom (2006), o profissional deve estar apto para agregar valor a essa interação cliente-empresa, pois para ter bom relacionamento, estes profissionais devem possuir as seguintes características: (1) Autossuficiência técnica; (2) Habilidades de comunicação; (3) Cortesia e empatia; (4) Capacidade de gerenciar crises; e (5) Autonomia para o mesmo autor, para saber se uma empresa conta com clientes fiéis ou não, a indicação para se medir a fidelidade é a de observar quantos clientes voltam a comprar e quantos compram mais, ano após ano. No Quadro 1, Las Casas (2013) elenca os riscos dos programas de fidelização que devem ser evitados pelas empresas.

Além de fidelizar clientes, o interessante e desejável é que esse relacionamento seja de longa duração, sendo assim, Madruga (2010) comenta que longevidade é a palavra de ordem para todas as pessoas que lidam com 
clientes ou que trabalham em atividades de suporte junto a eles. Assim, a empresa deve projetar recursos financeiros, materiais e humanos para o programa e jamais concorrer com outros projetos da empresa. Para o autor, identificar que tipo de recompensa o consumidor prioriza é imprescindível para que o programa seja aceito.

Silva e Zambom (2006) ressaltam a necessidade de utilizar o marketing de permissão, pois os clientes podem não gostar de ser incomodados com informações como as das campanhas publicitárias da organização. Os mesmos autores ressaltam, ainda, que conectar-se com o cliente é importante, mas com a permissão dele. A privacidade é uma das principais variáveis de vida que o cliente quer ver garantida.

\section{Metodologia}

A metodologia definida para a realização deste trabalho tem abordagem de natureza quantitativa e qualitativa. Richardson (1999) afirma que a pesquisa qualitativa auxilia no entendimento sobre um fenômeno que não se pretende quantificar, mas sim compreender suas características ou especificidades. Para Severino (2007), a pesquisa quantitativa concentra-se na objetividade, influenciada pelo positivismo, a qual considera que a realidade só pode ser compreendida com base em análise de dados brutos recolhidos com auxílio de instrumentos padronizados e neutros. Esse modelo de pesquisa recorre à linguagem matemática para descrever as causas de um fenômeno, as relações entre as variáveis, etc.

Em relação aos objetivos, caracteriza-se como descritiva. De acordo com Malhotra (2006), a pesquisa descritiva é um tipo de pesquisa conclusiva, que tem como principal objetivo a descrição de algo, normalmente caracteristicas ou funções de mercado, obtendo desta maneira as informações necessárias para responder o problema de pesquisa.

A respeito dos procedimentos técnicos para a realização desta pesquisa, optou-se por um estudo de caso. Martins (2006) explica que esse tipo de estudo é uma estratégia de pesquisa para a qual não se desenvolveu um conjunto fixo de etapas para conduzi-lo, assim como estudar em profundidade um caso específico - aqui, o objeto de estudo será a Cooperativa Agrícola Alfa e seus clientes.

Quanto ao plano de coleta dos dados, a pesquisa foi realizada com uma amostra composta por 66 clientes, através de uma amostragem não probabilística, por acessibilidade, no momento em que os mesmos compareceram na cooperativa ou receberam a visita do vendedor, isso porque grande parte reside em propriedades rurais.

O instrumento de coleta adotado foi um questionário formado por 14 questões fechadas e uma aberta, a fim de analisar a percepção dos clientes sobre o relacionamento com a cooperativa. Os dados obtidos foram tabulados com o auxílio do software Sphinx Léxica®, versão 5, sendo analisados sob a ótica qualitativa.

\section{Análise e discussão dos resultados}

\subsection{Caracterização da cooperativa Alfa}

A Cooperativa estudada localiza-se na região central do Estado do Rio Grande do Sul e opera no mercado há doze anos, tendo como ramo de atuação o agropecuário. Além dos colaboradores, a Cooperativa conta com a participação dos membros dos conselhos administrativo e fiscal, agrônomos e técnicos agrícolas e também com mais de mil e duzentos associados.

Deste modo, por ser uma cooperativa, é formada com base na colaboração dos seus associados e tem em comum o desenvolvimento e a prática do uso de uma agricultura tecnificada. Nesse sentido, promove o desenvolvimento e auxilia na compra do material necessário ao incremento de lavoura dos cooperados, visando a redução de custos e o aumento da produtividade. Além disso, se responsabiliza pelo recebimento, estocagem, secagem, beneficiamento e comercialização dos produtos de seus associados. E ainda, tem como missão possibilitar a integração entre todos os envolvidos: cooperativa, associados e o mercado. Para isso, a Cooperativa mantém contato contínuo com seus clientes, desde a venda de insumos até a organização do plantio, por isso, é de grande importância estudar o marketing de relacionamento, especificamente na Alfa, pois é através dele que se encontra grande parte do sucesso da Cooperativa. Na sequência, apresenta-se o perfil dos clientes e o relacionamento do cliente com a Cooperativa

\subsection{Perfil dos clientes entrevistados}

Silva e Zambom (2006) lembram da importância de se conhecer o perfil dos clientes, tanto dos atuais como também dos potenciais clientes, para se dedicar a eles e atender as suas expectativas. Deste modo, no caso da cooperativa analisada, a pesquisa apontou que 3\% dos clientes encontram-se na faixa etária de até 20 anos; $20 \%$ de 21 a 30 anos; $29 \%$ de 31 a 40 anos; $38 \%$ de 41 a 50 anos; e 10\% mais de 50 anos. Sendo a maioria, 91\% do gênero masculino e $8 \%$ do gênero feminino.

Quanto ao nível de escolaridade, constatou-se que $5 \%$ possuem o primeiro grau completo; $14 \%$ o segundo grau incompleto; $30 \%$ o segundo grau completo; $15 \%$ a graduação incompleta; $20 \%$ a graduação incompleta; $20 \%$ graduação completa; $3 \%$ pós-graduação incompleta; e $13 \%$ pós-graduação completa..

\subsection{Relacionamento do cliente com a cooperativa}

Conforme segue na Tabela 1 percebe-se que o maior

RGC - Vol. 01, $\mathrm{N}^{\circ} 02,2^{\circ}$ Sem. 2014, Págs. 01-12 
índice de clientes possui de 1 a 3 anos de relacionamento com a Cooperativa, ou seja, $30 \%$ dos entrevistados; e apenas $15 \%$ possuíam um tempo de relacionamento menor do que o período de 1 ano.

A Tabela supracitada aborda também sobre os canais de comunicação, sendo que a pesquisa aponta que o maior percentual advém de contato pessoal direto (53\%); seguido pelo contato via telefone (33\%); enquanto o e-mail não obteve uma alta pontuação. Assim sendo, pode-se dizer que na Cooperativa predomina a comunicação oral com conversas face a face e também por meio de telefonemas (GRIFFIN, 2007).

Outro tema abordado refere-se aos fatores que determinam o relacionamento, a ordem decrescente do percentual é a seguinte: relacionamento de parceria (29\%); confiabilidade da instituição $(20 \%)$; rapidez na solução de problemas (17\%); atendimento cortês (12\%); facilidade de contato pessoal (11\%); localização (7\%); e atendimento personalizado (4\%).

Tais resultados corroboram com o que recomenda Cobra (2008) a fim de maximizar negócios a longo prazo nesse processo de troca, como a questão do relacionamento de cumplicidade da empresa para com seus clientes, atendendo suas necessidades e antecipando-se à concorrência.

Em relação a localização da Cooperativa, identificou-se que é extremamente importante para os clientes da Alfa, isso porque $89 \%$ dos entrevistados concordam totalmente que a localização é importante para o relacionamento com o cliente.

Na Tabela 1 foi abordada também a percepção do cliente quanto à seguinte afirmação: "A empresa facilita o contato pessoal e a integração com o cliente", onde $71 \%$ concordam totalmente com a afirmação e os demais apenas concordaram.

Dessa forma, verificou-se que a maioria $(85 \%)$ dos clientes mantém um relacionamento com a empresa superior a 1 ano, pelo ramo da empresa que é uma cooperativa agrícola, bem como pelo perfil do entrevistado, homens com mais de 20 anos e menos de 50 anos, a maior parte do contato ocorre pessoalmente.

Constatou-se também que o principal fator de determinação da parceira é o próprio relacionamento de parceria, resultado esperado para uma cooperativa. A localização foi confirmada como um fator importante para o relacionamento e a facilidade do contato pessoal e integração com o cliente foi visto como um fator positivo na referida cooperativa analisada.

A Tabela 2 inicia com a afirmação: "O atendimento dos funcionários é cortês e educado", e nesse item a maioria (64\%) concordou totalmente com a afirmação; enquanto $36 \%$ apenas concordaram. Posteriormente, foi questionado se a Cooperativa pratica um atendimento personalizado, onde se obteve como retorno 39\% concordando totalmente; para $14 \%$ esse é um aspecto indiferente, enquanto os demais apenas concordaram.

Percebe-se ainda, na Tabela 2, que a visita dos engenheiros agrônomos nas propriedades dos clientes é importante para melhorar o relacionamento, onde a maioria (68\%) concorda totalmente; outros $29 \%$ concordam; e apenas 3\% se mostraram indiferentes.

Destaca-se que essa indiferença pode ser originária de uma insatisfação com o serviço prestado, por isso, recomenda-se que a cooperativa procure investigar o que não está atendendo às expectativas do seu cliente, gerando essa insatisfação. Isso porque clientes insatisfeitos, além de não voltarem a comprar na empresa, também irão repassar sua opinião negativa para outras pessoas (LAS CASAS, 2006).

Na sequência, a Tabela 3 dispõe que a rapidez na solução é importante para um bom relacionamento, onde $79 \%$ dos entrevistados concordavam totalmente e $21 \%$ concordaram parcialmente.

Inicialmente, a Tabela 3 contempla a questão do relacionamento cliente-empresa com a fidelidade, sendo que $59 \%$ dos entrevistados concordaram totalmente com a relação; e 36\% concordaram parcialmente. Nesse sentido, Madruga (2010) enfatiza que uma empresa saudável, com consumidores valiosos por um longo tempo, obtém resultados suficientes para investir na criação de valores e benefícios.

Ademais, 32\% dos entrevistados confiam totalmente nos produtos e serviços oferecidos pela cooperativa; enquanto que a maioria $(64 \%)$ concorda parcialmente nesse item, provavelmente, isso se deve ao fato desses clientes serem esporádicos..

Sobre o marketing de relacionamento 59\% dos entrevistados concordaram totalmente que o mesmo melhora a prestação dos serviços. Complementarmente, D'Angelo, Schneider e Larán (2006) entendem que essa relação de longo prazo é o que o marketing de relacionamento se propõe, sendo uma filosofia empresarial construindo e mantendo um relacionamento com cada cliente.

Posteriormente, foi pedido quais são as contribuições do marketing de relacionamento, onde para $42 \%$ a maior contribuição incide na prestação de serviços com maior qualidade; outros 30\% na prestação do serviço mais rápida; e para $28 \%$ incide na maior confiança ao serviço prestado.

Em relação à frase: "Pretende manter ou aumentar o relacionamento com a Cooperativa", nota-se que $36 \%$ concordam totalmente; enquanto que $47 \%$ concordam; e $17 \%$ se mostraram indiferentes ao questionamento realizado. No que se refere ao nível de satisfação com a cooperativa, percebe-se que a maioria $(68 \%)$ considerou ótimo; enquanto que $32 \%$ avaliaram em um nível bom.

Sob esse enfoque, Las Casas (2013) apenas alerta as empresas no sentido de dar atenção para a qualidade, elemento este que está relacionado com a satisfação do 
Tabela 1 - Relacionamento do cliente com a cooperativa (Parte I)

\begin{tabular}{|c|c|c|}
\hline \multicolumn{3}{|c|}{ Tempo de relacionamento com a cooperativa } \\
\hline Tempo & Frequência & Percentual \\
\hline Mais de 10 anos & 0 & $0 \%$ \\
\hline De 7 a 10 anos & 3 & $5 \%$ \\
\hline De 4 a 6 anos & 9 & $14 \%$ \\
\hline De 1 a 3 anos & 20 & $30 \%$ \\
\hline Menos de 1 ano & 10 & $15 \%$ \\
\hline \multicolumn{3}{|c|}{$\begin{array}{l}\text { Canais de comunicação mais utilizados pelo cliente para comunicar-se a } \\
\text { cooperativa }\end{array}$} \\
\hline Contato & Frequência & Percentual \\
\hline Pessoal & 35 & $53 \%$ \\
\hline Internet (e-mail etc.) & 9 & $14 \%$ \\
\hline Telefone & 22 & $33 \%$ \\
\hline \multicolumn{3}{|c|}{ Principais fatores que na determinação do relacionamento } \\
\hline Fatores & Frequência & Percentual \\
\hline Relacionamento de parceria & 19 & $29 \%$ \\
\hline Facilidade de contato pessoal & 7 & $11 \%$ \\
\hline Rapidez na solução de & & \\
\hline problemas & 11 & $17 \%$ \\
\hline Confiabilidade da instituição & 13 & $20 \%$ \\
\hline Atendimento personalizado & 3 & $4 \%$ \\
\hline Atendimento cortês & 8 & $12 \%$ \\
\hline Localização & 5 & $7 \%$ \\
\hline \multicolumn{3}{|c|}{ A localização da cooperativa é importante para o bom relacionamento } \\
\hline Localização da cooperativa & Frequência & Percentual \\
\hline Concordo totalmente & 59 & $89 \%$ \\
\hline Concordo & 7 & $11 \%$ \\
\hline Indiferente & 0 & $0 \%$ \\
\hline Discordo & 0 & $0 \%$ \\
\hline Discordo totalmente & 0 & $0 \%$ \\
\hline \multicolumn{3}{|c|}{ A cooperativa facilita o contato pessoal e a integração com o cliente } \\
\hline Contato pessoal e & & \\
\hline integração & Frequência & Percentual \\
\hline Concordo Totalmente & 47 & $71 \%$ \\
\hline Concordo & 19 & $29 \%$ \\
\hline Indiferente & 0 & $0 \%$ \\
\hline Discordo & 0 & $0 \%$ \\
\hline Discordo totalmente & 0 & $0 \%$ \\
\hline
\end{tabular}


Tabela 2 - Relacionamento do cliente com a cooperativa (Parte II)

\begin{tabular}{lcc}
\hline \multicolumn{3}{c}{ O atendimento dos funcionários da cooperativa é cortês e educado } \\
\hline Atendimento dos funcionários & Frequência & Percentual \\
Concordo totalmente & 42 & $64 \%$ \\
Concordo & 24 & $36 \%$ \\
Indiferente & 0 & $0 \%$ \\
Discordo & 0 & $0 \%$ \\
Discordo totalmente & 0 & $0 \%$ \\
\hline \multicolumn{1}{c}{ A cooperativa pratica um atendimento personalizado com o cliente } \\
\hline Atendimento personalizado & Frequência & Percentual \\
Concordo totalmente & 26 & $39 \%$ \\
Concordo & 31 & $47 \%$ \\
Indiferente & 9 & $14 \%$ \\
Discordo & 0 & $0 \%$ \\
Discordo totalmente & 0 & $0 \%$ \\
\hline A visita dos engenheiros agrônomos é importante para melhorar o relacionamento \\
\hline Visita dos engenheiros agrônomos & Frequência & Percentual \\
Concordo totalmente & 45 & $68 \%$ \\
Concordo & 19 & $29 \%$ \\
Indiferente & 2 & $3 \%$ \\
Discordo & 0 & $0 \%$ \\
Discordo totalmente & 0 & $0 \%$ \\
\hline \multicolumn{1}{c}{ A rapidez na solução de problemas é importante para um bom relacionamento } \\
\hline Rapidez na solução de problemas & Frequência & Percentual \\
Concordo totalmente & 52 & $79 \%$ \\
Concordo & 14 & $21 \%$ \\
Indiferente & 0 & $0 \%$ \\
Discordo & 0 & $0 \%$ \\
Discordo totalmente & 0 & $0 \%$ \\
\hline
\end{tabular}

Fonte: Elaborado pelos autores com base nos dados da pesquisa.

cliente. Mas, de modo geral, a análise dos dados obtidos na pesquisa revelou que o relacionamento entre cliente e Cooperativa vem atingindo bons resultados, fidelizando os mesmos de forma com que se sintam satisfeitos.

Assim sendo, vale trazer o exposto por Madruga (2010), ao comentar que a fidelização dos clientes com uma empresa não é eterna, mas, quanto maior o tempo de duração da relação, maiores as chances de benefícios mútuos.

\section{Considerações Finais}

Com a realização desse estudo, foi possível analisar o marketing de relacionamento na Cooperativa Agrícola Alfa, obtendo a opinião dos clientes a fim de poder reter seus principais desejos e visando atender da melhor forma esse público, para que essa relação seja cada vez mais duradoura.

A cooperativa em questão busca sempre atender seu cliente da melhor forma possível, oferecendo a eles alguns serviços diferenciados, tais como: o auxílio na compra de maquinários, realização de projetos nas lavouras, com o intuito de obter melhorias para os colonos e, às vezes, sem cobrar nada por estes serviços, fidelizando cada vez mais este público.

Verificou-se, através dos resultados obtidos, que entre os aspectos mais valorizados pelos clientes no relacionamento com a Cooperativa estão: a localização; a rapidez na solução de problemas; o contato pessoal e a integração com o cliente; o atendimento cortês e educado; a visita dos engenheiros agrônomos; como também, o relacionamento entre o agricultor e a Cooperativa; e, ainda, a confiança nos produtos e serviços oferecidos. 
Tabela 3 - Relacionamento do cliente com a cooperativa (Parte III)

\begin{tabular}{|c|c|c|}
\hline $\begin{array}{c}\text { Relacionamento entre o cliente e a } \\
\text { cooperativa }\end{array}$ & Frequência & Percentual \\
\hline Concordo Totalmente & 39 & $59 \%$ \\
\hline Concordo & 24 & $36 \%$ \\
\hline Indiferente & 3 & $5 \%$ \\
\hline Discordo & 0 & $0 \%$ \\
\hline Discordo Totalmente & 0 & $0 \%$ \\
\hline \multicolumn{3}{|c|}{ Confiança nos produtos e serviços oferecidos na cooperativa } \\
\hline Confiança nos produtos e serviços & Frequência & Percentual \\
\hline Concordo totalmente & 21 & $32 \%$ \\
\hline Concordo & 42 & $64 \%$ \\
\hline Indiferente & 3 & $4 \%$ \\
\hline Discordo & 0 & $0 \%$ \\
\hline Discordo totalmente & 0 & $0 \%$ \\
\hline \multicolumn{3}{|c|}{ O marketing de relacionamento melhora a prestação dos serviços } \\
\hline Melhora a prestação dos serviços & Frequência & Percentual \\
\hline Concordo totalmente & 39 & $59 \%$ \\
\hline Concordo & 27 & $41 \%$ \\
\hline Indiferente & 0 & $0 \%$ \\
\hline Discordo & 0 & $0 \%$ \\
\hline Discordo totalmente & 0 & $0 \%$ \\
\hline \multicolumn{3}{|c|}{ Contribuições do marketing de relacionamento } \\
\hline Contribuições & Frequência & Percentual \\
\hline Prestação de serviços mais rápida & 20 & $30 \%$ \\
\hline Prestação de serviços de melhor qualidade & 28 & $42 \%$ \\
\hline Na confiança dos serviços prestados & 18 & $28 \%$ \\
\hline \multicolumn{3}{|c|}{ Pretende manter ou aumentar o relacionamento com a cooperativa } \\
\hline Relacionamento com a cooperativa & Frequência & Percentual \\
\hline Concordo totalmente & 24 & $36 \%$ \\
\hline Concordo & 31 & $47 \%$ \\
\hline Indiferente & 11 & $17 \%$ \\
\hline Discordo & 0 & $0 \%$ \\
\hline Discordo totalmente & 0 & $0 \%$ \\
\hline \multicolumn{3}{|c|}{ Nível de satisfação com a cooperativa em geral } \\
\hline Nível de satisfação & Frequência & Percentual \\
\hline Ótimo & 45 & $68 \%$ \\
\hline Bom & 21 & $32 \%$ \\
\hline Regular & 0 & $0 \%$ \\
\hline Ruim & 0 & $0 \%$ \\
\hline
\end{tabular}

Fonte: Elaborado pelos autores com base nos dados da pesquisa. 
Deste modo, concluiu-se que é de extrema importância o marketing de relacionamento no preocesso de integração do cliente com a Cooperativa. Destacandose, de acordo com o estudo, a rapidez na solução de problemas, pois $79 \%$ dos entrevistados concordam totalmente que este fator é importante para um bom relacionamento; e 21\% concordam com a afirmação, pois no ramo da agricultura é fundamental que os problemas sejam resolvidos o mais brevemente possível, isso porque, em função das variações climáticas, o produtor precisa estar bem amparado, portanto, a Cooperativa deve tentar sanar os problemas com rapidez, possibilitando assim, formular novas técnicas a partir do que se aprendeu sobre eles. O conhecimento dos dados do cliente possibilita realizar serviços que venham atender às necessidades dos seus clientes.

Assim, recomenda-se que a Cooperativa Alfa continue com os serviços diferenciados prestados e que os seus vendedores continuem a desenvolver este atendimento da melhor forma possível, agregando cada vez mais este relacionamento de parceria.

Todavia, identificou-se que a Cooperativa ainda encontra certas dificuldades para se comunicar com alguns clientes da zona rural e que, às vezes, eles têm certo receio de se adaptar às novas tecnologias existentes no mercado.

Portanto, sugere-se que a Cooperativa se preocupe em aumentar esta comunicação através de seus vendedores, visitando mais vezes tais clientes que se mantêm distanciados da empresa, a fim de mostrar e esclarecer as dúvidas sobre esses produtos novos, aumentando dessa forma o marketing de relacionamento e possível fidelização.

Como sugestão para novos estudos, recomenda-se que mais trabalhos como este sejam desenvolvidos em outras cooperativas do Estado do Rio Grande do Sul com o intuito de comparar os resultados obtidos, como também, identificar como está o marketing de relacionamento com seus respectivos clientes e associados, tendo como propósito manter uma parceria duradoura e com as necessidades atendidas.

\section{Referências}

AGARIYA, A. K.; SINGH, D. What really defines relationship marketing? A review of definitions and general and sector-specfic defining constructs. Journal of Relationship Marketing, v. 10, n. 4, p. 203-237, 2011.

ASHLEY, C.; NOBLEB, S. M.; DONTHUC, N.; LEMOND, K. N. Why customers won't relate: Obstacles to relationship marketing engagement. Journal of Business Research, v. 64, n. 7, p. 749-756, 2011.
BARRIONUEVO, F. Z. Relacionamento com clientes: a evolução do marketing e a presença da tecnologia num ambiente de negócios b2b. PIRACICABA, São Paulo, 2004. Disponível em: <http://www.ebah.com. br/content/ABAAABHTYAK/relacionamento-comclientes> Acesso em: 27 jun. 2013.

BONNEMAIZON, A.; COVA, B.; LOUYOUT, MarieClaude. Relationship marketing in 2015: a Delphi approach. European Management Journal, v. 25, n. 1, p. 50-59, 2007.

CHURCHILL JUNIOR, G.; PETER, J. P. Marketing: criando valor para o cliente. 3. ed. São Paulo: Saraiva, 2013.

COBRA, M. Administração de marketing no Brasil. 3. ed. São Paulo: Cobra Editora de Marketing, 2008.

D'ANGELO, A. C.; SCHNEIDER, H.; LARAN, J. A. Marketing de relacionamento junto a consumidores finais: um estudo exploratório com grandes empresas brasileiras. Revista de Administração Contemporânea, v.10, n.1, p. 73-93, 2006.

ETZEL, M. J.; WALKER, B. J.; STANTON, W. J. Marketing. São Paulo: Makron Books, 2001.

GREENBERG, P. CRM na velocidade da luz. Rio de Janeiro: Campus, 2001.

GRIFFIN, R. W. Introdução à administração. São Paulo: Ática, 2007.

KELLEZI, J. Trade shows: a strategic marketing tool for Global Vompetition. Procedia Economics and Finance, v. 9, 2014, p. 466-471, 2014.

KOTLER, P.; ARMSTRONG, G. Princípios de marketing. 7. ed. Rio de Janeiro: LTC, 1999.

KOTLER, P.; KELLER, K. L. Administração de marketing. 12. ed. São Paulo: Pearson Pretice Hall, 2007.

LAS CASAS, A. L. Administração de marketing: conceitos, planejamento e aplicações à realidade brasileira. São Paulo: Atlas, 2006. 2012.

. Marketing de serviços. 6. ed. São Paulo: Atlas, 2013.

Marketing de varejo. 5. ed. São Paulo. Atlas:

MADRUGA, R. Guia de implementação de marketing 
de relacionamento e CRM. 2. ed. São Paulo: Atlas, 2010 .

MALHOTRA, N. Pesquisa de marketing: uma orientação aplicada. 4. ed. Porto Alegre: Bookman, 2006.

MARTINS, G. de A. Estudo de caso: uma estratégia de pesquisa. São Paulo: Atlas, 2006.

MÖLLER, K. Theory map of business marketing: relationships and networks perspectives. Industrial Marketing Management, v. 42, n. 3, p. 324-335, 2013.

MUSA, S.; BONIFACE, B.; TANAKINJAL, G. Relationship marketing moderating effect on value chain of horticulture produce: an intermediaries' perspective. UMK Procedia, v. 1, 2014, p. 82-92, 2014.

RICHARDSON, R. J. Pesquisa social: métodos e técnicas. 3. ed. São Paulo: Atlas, 1999.

SEVERINO, A. J. Metodologia do trabalho científico. 23. ed. São Paulo: Cortez, 2007.

SHETH, J. N. Comportamento do cliente. São Paulo: Atlas, 2001.

SHETH, J. N.; PARVATIYAR, A.; SINHA, M. The conceptual foundations of relationship marketing: review and synthesis. Economic sociology, v. 13, n. 3, 2012.

SILVA, D. B. dos S.; MARCHESINI, F. R. de A.; OLIVEIRA, J. A. F. de; SÁ, L. C. S. de. Fundamentos de marketing. 4. ed. Rio de Janeiro: FGV, 2011.

SILVA, F. G. da; ZAMBOM, M. S. Gestão do relacionamento com o cliente. São Paulo: Thomson Learning, 2006.

YANAZE, M. Gestão de marketing e comunicação: avanços e aplicações. São Paulo: Saraiva, 2007. 
